\title{
Influence of Different Nitrogen Norms on the Collection of Nutrients in Tomato Plant in the Background of Organic Fertilizers
}

\author{
ZH Aliyev* and K Aliyeva \\ Institute of Soil Science and Agro chemistry of ANAS, Azerbaijan \\ *Corresponding author: ZH Aliyev, Institute of Soil Science and Agro chemistry of ANAS, Azerbaijan
}

Submission: 䟧 April 04, 2018; Published: 眥 May 25, 2018

\begin{abstract}
Annotation
Determination of optimal fertilizer norms under tomato vegetation related to vegetable growing is a very important issue. For this purpose, the influence of various norms of nitrogen on the background of organic fertilizers on the background of the biometric data of the "Preliminary" tomato varieties, the total nitrogen, phosphorus and potassium content of tomato bushes have been studied. Also, the biochemical indicators of tomatoes were studied. It has been shown that no fertilization of the fertilizers in the fertilizer (10t/ha) $+N_{90} P_{90} K_{90}$ was observed in the fertilizer, but the tomato fruit weight and diameter increased, and the nitrates contained in it did not exceed the norm.
\end{abstract}

Keywords: Tomato; Nitrogen; Plant height; Fruit

\section{Introduction}

The intensive growth of the world population and the restriction of soil and water resources caused a serious problem for the safety of human nutrition in the world. Only 3\% of water resources of fresh water. Accoding to the report of FAO, if in any country the amount of fresh water is less than $1700 \mathrm{~m} 3$ per capita, this country faces a shortage of serous water. Currently, the share of fresh water per capita in less than $100 \mathrm{~m} 3$ in 18 countries is more than $2000 \mathrm{~m} 3$ in 22 countries. Consequently, Azerbaijan is one of the countries with a shortage of water resources problems in the sphere of agricultural production and the population as a whole.

Therefore, it is necessary and take into account for this purpose the optimum humidity and ground temperature in the production management system up to the agricultural product, which is necessary first of all for making operative decisions when developing environmentally friendly technology for growing crops to achieve maximum yield. However, it should be recognized that of the number of crops grown in these conditions, and tomatoes occupy a special place, which requires a special approach to solving the problems ahead.

Tomatoes are one of the most cultivated vegetables in the world. Fertilization with nitrogen is due to an increase in the amount of photosynthesis source, affecting the growth of vegetative growth and biomass [1]. Growth phase and environmental conditions should be taken into account when selecting the optimum nitrogen norm according to the requirements of the fertilized plant. However, during the growth phase, producers typically tend to restrict the use of nitrogen because excessive dose may cause excessive growth of vegetative growth.

In fact, it provides growth of vegetative growth from reproductive development, leads to frustration, fertility loss, insect damage, as well as increased herbal diseases and contribute to the weak development of flower, fruits and their size. This is basically true in the most favorable conditions during high rainfall and humidity. In order to increase productivity in fruits and reproductive development, the norm of nitrogen is increased.

Nitrogen deficiency results in the faded leaves of the plants and their neck low. First of all, due to the circulation of nutrients in the plant, the deficiency is manifested in older leaves. The flowers begin to play in dark yellow, and in the sharp state of nitrogen deficiency, they are poured, fruits are smaller, which affects productivity. Excessive nitrogen fertilization results in the formation of dark green leaves. Although the number of flowers is very high, buds remain intact. It also prevents flowers, fruits and their formation, and increases the inclination of the plant to bend, banish disease and attack the pests [2].

Increase in the norm of nitrogen fertilizer from 0 to $200 \mathrm{~kg} /$ ha leads to the increase of tomato productivity and improvement of fruit quality. There are important differences between the nutritional quality of organic and traditional grown tomatoes. Carotenoid accumulation and antioxidant activity in organic tomatoes grows. Nitrogen is one of the key elements of plant growth and development. It plays an important role in the nutrition 
of plants, and is thus factor limiting plant productivity in many areas, especially in weak organic lands.

Nitrogen fertilizers are often transported on land, polluting soil and groundwater. So it should be controlled for nitrogen fertilizer: the norm, the type of nitrogen fertilizer, and the duration of delivery [3]. The purpose of this research is to evaluate the effect of the amount of nitrogen on the background of organic fertilizers in collecting common nitrogen, phosphorus and potassium in the quality of tomatoes and tomato bushes on gray-brown soils.

\section{Materials and Methods}

The research was carried out in the field of expertise of the Institute of Vegetable Science Scientific Research Institute of the Ministry of Agriculture of the Republic of Azerbaijan in the territory of Absheron region (Pirshagy massif). The width of the research area is $40^{\circ} 31^{\prime}$, its length is $49^{\circ} 52^{\prime}$, at the altitude of 20.4-34.7 meters above the Caspian Sea level [4]. The amount of sunny hours is $2400-2500$ per year. The climate is very dry - the spring is warm and long, the winter is moderate. Average annual temperature is $-14{ }^{\circ} \mathrm{C}$. The lowest temperatures are $2.8-3.4^{\circ} \mathrm{C}$ in January and $25.5-$ $25.7{ }^{\circ} \mathrm{C}$ in July. Favorable conditions for the development of plants continue from March to October.

In the study area average annual sediments are $150-300 \mathrm{~mm}$. Rainfall in summer is very coincident and its duration is short. Biological and biochemical processes in the study area are subject to acute shortage of moisture. Water sources are very poor. The water for irrigation is taken from the Absheron canal. Artificial irrigation is needed for the normal development of vegetable crops [5]. The experiments were conducted with "Primary" tomato sort. "Primary" sort was obtained by crossing the 294-VD1-D1-DVK-DVK and Brigantine varieties [6].
"Initial" is the first localized sort of canned food. The handle is ordinary, determinant type, medium leaf. The leaves are of ordinary type, large $(28-37 \mathrm{~cm})$, green, surface is brittle. Flowerpots are simple, medium-sized $(13-16 \mathrm{~cm})$. According to the length of the vegetation period, "Initial" is a group of medium-grown varieties. Thus, the length of the period from the occurrence of the mass seedlings to the first fruits is 110 . The experiments were performed 4 times for the purpose of obtaining high yields from "primary" tomato varieties, with the area of each unit $15,12 \mathrm{~m} 2$ being $70 \mathrm{~cm}$ in diameter and $30 \mathrm{~cm}$ from the plant distance $[4,6]$.

The scheme of practice is as follows:

1. Control (no fertilizer)

2. Pentecost (10t/ha) + N0P90K90 (Background)

3. Background $+\mathrm{N} 30$

4. Background $+\mathrm{N} 60$

5. Background $+\mathrm{N} 90$

After tomato seedlings were buried in mid-May, soil fertilized, nitrogen fertilizer, ammonium nitrate (NH4NO3- 34\%), where nitrogen is $25 \%$ of the total norm. One month later, as a firstfertilizer fertilizer, carbamide fertilizer ( $\mathrm{CO}(\mathrm{NH} 2)-46 \%$ ) was added to the soil, where nitrogen was $50 \%$ of the total norm, and a month later, again, and nitrogen constitutes $25 \%$ of the total norm.

\section{Results and Diversion}

The height and root of the plant during adulthood: In the experimental field a number of observations have been made on tomato plant. The length of the tomato leaf was measured centrally from the ground to the highest point of the plant (on 10 plants) and the common figure was removed. Also, the root length of the plant is measured. The results are given in (Table 1).

Table 1: Tall height of the tomato plant and the length of the root (during the ripening period- $72^{\text {nd }}$ day).

\begin{tabular}{|c|c|c|c|c|c|c|}
\hline \multirow{2}{*}{ Practice Options } & \multirow{2}{*}{$\begin{array}{c}\text { The Height of the } \\
\text { Tomato Plant ( } 72 \\
\text { Days) cm }\end{array}$} & \multicolumn{2}{|c|}{ Increase } & \multirow{2}{*}{$\begin{array}{c}\text { The Root Length } \\
\text { of the Plant (In } 72 \\
\text { days) }\end{array}$} & \multicolumn{2}{|c|}{ Increase } \\
\hline & & $\mathbf{c m}$ & $\%$ & & $\mathbf{c m}$ & $\%$ \\
\hline $\begin{array}{l}\text { Control (no } \\
\text { fertilizer) }\end{array}$ & 59.3 & - & - & 20.5 & - & - \\
\hline $\begin{array}{l}\text { Peanut }\left(10_{t} /\right. \\
\text { ha) + N0P90K } \\
\text { (Background) }\end{array}$ & 66.3 & 7.0 & 11.8 & 23.0 & 2.5 & 12.2 \\
\hline Background $+\mathrm{N}_{30}$ & 67.5 & 8.2 & 13.8 & 24.5 & 4.0 & 19.5 \\
\hline Background $+\mathrm{N}_{60}$ & 68.0 & 8.7 & 14.7 & 25.5 & 5.0 & 24.4 \\
\hline Background $+\mathrm{N}_{90}$ & 71.5 & 12.2 & 20.6 & 31.0 & 9.5 & 46.3 \\
\hline
\end{tabular}

As seen from (Table 1) the height of the tomato plant is higher than the effect of fertilizers given in 72 days (fertilization): $10 \mathrm{~kg} /$ ha+ N0P90K90 in the nitrogen value of $30 \mathrm{~kg}$ of active substance in the background, $\mathrm{cm}$ or $13.8 \%$; in the same nitrogen variant with $60 \mathrm{~kg}$ of active substance in the same background, on an average of about $8.7 \mathrm{~cm}$ or $14.7 \%$ of a plant in the same nitrogen variant with $90 \mathrm{~kg}$ of active substance, height increased by $12.2 \mathrm{~cm}$ or $20.6 \%$. Also, the root length of the tomato plant has increased by an average of $9.5 \mathrm{~cm}$ or $46.3 \%$ compared to the control variants in the nitrogen variant with $90 \mathrm{~kg}$ of active substance on the background (10t /ha)+N0P90K90.

\section{Nutrients in the plant's arm during adulthood}

During the growing period of tomato herbicides, two cane roots were removed from each variant, both large and small. The tomatoes on them were torn, and the plant branches were dried in 
the shade, then dried in a thermostat. Then, the roots, stems and leaves of the plant were mixed, and the total nitrogen, phosphorus and potassium were analyzed.

The results are given in (Table 1). As can be seen from the table, the amount of nitrogen, phosphorus and potassium in the tomato plant does not exceed the norm in all variants. Weight and diameter Table 2: Foodstuffs collected in the tomato plant branch. of ripe tomatoes: Each sample was taken from 10 ripe tomatoes, weighted and diameter was measured, then a common figure was found (Table 2). As shown in (Table 3) as the nitrogen norms increase, tomato fruit weight and diameter increase also. Of course, as a background, manure, phosphorus and potassium fertilizers are also provided.

\begin{tabular}{|c|c|c|c|c|c|c|c|}
\hline \multirow{2}{*}{ Order } & \multirow{2}{*}{ Practice Options } & \multirow{2}{*}{$\begin{array}{c}\text { Weight of } \\
\text { Tomato Fruit. } \\
\text { (qr) }\end{array}$} & \multicolumn{2}{|c|}{ Increase } & \multirow{2}{*}{$\begin{array}{l}\text { The Diameter of } \\
\text { the Tomato Fruit. } \\
\text { (cm) }\end{array}$} & \multicolumn{2}{|c|}{ Increase } \\
\hline & & & $\mathbf{q r}$ & $\%$ & & sm & $\%$ \\
\hline 1 & Control (no fertilizer) & 134.3 & - & - & 6.7 & - & - \\
\hline 2 & $\begin{array}{l}\text { Manure }\left(10_{\mathrm{t}} / \mathrm{ha}\right)+ \\
\mathrm{N}_{0} \mathrm{P}_{90} \mathrm{~K}_{90} \text { (Fon) }\end{array}$ & 138.6 & 4.3 & 3.2 & 6.8 & 0.1 & 1.5 \\
\hline 3 & Background $+\mathrm{N}_{30}$ & 147.1 & 12.8 & 9.5 & 7.0 & 0.3 & 4.5 \\
\hline 4 & Background $+\mathrm{N}_{60}$ & 150.1 & 15.8 & 11.8 & 7.2 & 0.5 & 7.5 \\
\hline 5 & Background $+\mathrm{N}_{90}$ & 156.4 & 22.1 & 16.5 & 7.2 & 0.5 & 7.5 \\
\hline
\end{tabular}

Table 3: Weight and diameter of tomato fruit.

\begin{tabular}{|c|c|c|c|}
\hline \multirow{2}{*}{ Practice Options } & Total Nitrogen (\%) & Common Phosphorus (ppm) & Total Potassium (ppm) \\
\cline { 2 - 4 } & \multicolumn{3}{|c|}{ The name of the method } \\
\cline { 2 - 4 } & (Kjeldahl) & (Age-burning ICP-OES) & (Age-burning ICP-OES) \\
\hline Control (no fertilizer) & 1.89 & 3325 & 23480 \\
\hline $\begin{array}{c}\text { Peanut }\left(10_{\mathrm{t}} / \text { ha) }+\mathrm{N}_{90} \mathrm{P}_{90} \mathrm{~K}_{90}\right. \\
\text { (Background) }\end{array}$ & 2.24 & 3530 & 25380 \\
\hline Background $+\mathrm{N}_{30}$ & 2.41 & 3776 & 31410 \\
\hline Background $+\mathrm{N}_{60}$ & 2.42 & 3864 & 31730 \\
\hline Background $+\mathrm{N}_{90}$ & 2.42 & 4298 & 34950 \\
\hline
\end{tabular}

\section{Biochemical indicators of tomatoes}

A sample of tomatoes was sampled and analyzed from the nitrogen variant with $90 \mathrm{~kg}$ of active ingredient in the background of $10 t$ /ha of the experimental scheme. As a result of biochemical analysis it was found out that the content of "Ilkin" tomato was $7.5 \%$, sugar was $3.6 \%$, total acidity was $0.39 \%$, vitamin C was $24.86 \%$, nitrate was $96.7 \mathrm{ppm}$. As it has been seen here, the norm of nitrogen has not been exceeded in the amount of nitrates contained in the tomatoes for the open field.

\section{Conclusion}

Compared to the results of the observations, the amount of nitrogen given as an ingredient in the background (10t/ha) + N0P90K90, compared with the control variant, increased by $12.2 \mathrm{~cm}$ or $20.6 \%$, and was $71.5 \mathrm{~cm}$. The weight and diameter of the tomato fruit has also increased, and there are no adverse effects in biochemical parameters (Figure 1). Also, the removal of fertilizers to the norm (10t/ha)+N90P90K90 from the control (fertilized) variant did not result in excessive accumulation of excess nitrogen, phosphorus and potassium in the tomato plant.
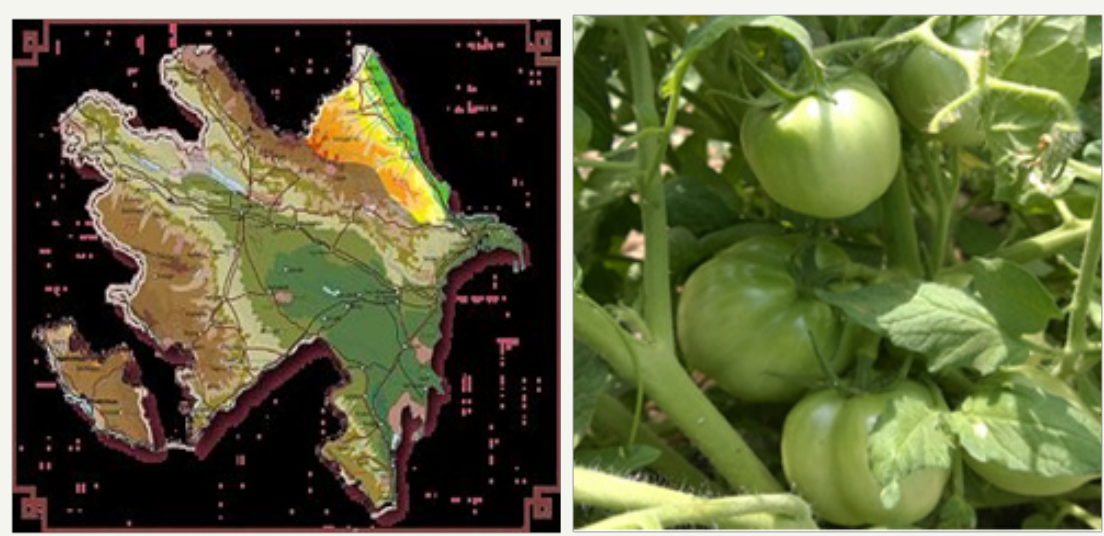

Figure 1: The weight and diameter of the tomato fruit has also increased. 


\section{References}

1. Tei F, Benincasa P, Guiducci M (2002) Critical nitrogen concentration in processing tomato. European Journal of Agronomy 18(1-2): 45-55.

2. Jones JB (1999) Tomato Plant Culture: In the Field Greenhouse and Home Garden. CRC Press LLC, USA, pp: 199.

3. De Pascale S, Tamburrino R, Maggio A, Barbieri G, Fogliano V, et al. (2006) Effect of nitrogen fertilization on the nutritional value of organically and conventionally grown tomatoes. Acta Hort 700: 107-110.
4. Aliyeva KA (2018) Absheron in the gray-brown soils of tomato in the biometric indicators and on the background of organic fertilizers. ANAS Soil science and Agro chemistry 1-2: 365-368.

5. Hasanov YC (2013) Monitoring of agro physical properties of irrigated soils of Azerbaijan. Azerbaijan, pp: 230.

6. Babayev AH, Aliyeva ZQ Huseynov HA (2012) Methodological aids for the initial seeding of Tohum's open field Ilkin Leyla Sugar and Perspective Victory varieties. Azerbaijan, pp: 46.

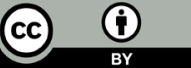

Creative Commons Attribution 4.0 International License

For possible submissions Click Here

\section{Submit Article}

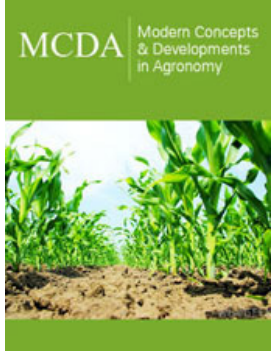

Modern Concepts \& Developments in Agronomy

\section{Benefits of Publishing with us}

- High-level peer review and editorial services

- Freely accessible online immediately upon publication

- Authors retain the copyright to their work

- Licensing it under a Creative Commons license

- Visibility through different online platforms 